Article

\title{
A High-Frequency Isolated Online Uninterruptible Power Supply (UPS) System with Small Battery Bank for Low Power Applications
}

\author{
Muhammad Aamir ${ }^{1,2, *}$, Wajahat Ullah Tareen ${ }^{2}$, Kafeel Ahmed Kalwar ${ }^{3}$, \\ Mudasir Ahmed Memon ${ }^{2}$ and Saad Mekhilef ${ }^{2}$ \\ 1 Department of Electrical Engineering, Bahria University, Islamabad 44000, Pakistan \\ 2 Power Electronics and Renewable Energy Research Laboratory (PEARL), Department of Electrical \\ Engineering, University of Malaya, Kuala Lumpur 50603, Malaysia; wajahattareen@gmail.com (W.U.T.); \\ memon.mudasir@usindh.edu.pk (M.A.M.); saad@um.edu.my (S.M.) \\ 3 Department of Electrical Engineering, DHA Suffa University, Karachi 75500, Pakistan; \\ kafeel_kalwar@yahoo.com \\ * Correspondence: muhammadaamir.buic@bahria.edu.pk
}

Academic Editor: Gabriele Grandi

Received: 22 December 2016; Accepted: 17 March 2017; Published: 23 March 2017

\begin{abstract}
Uninterruptible power supplies (UPSs) are widely used to deliver reliable and high quality power to critical loads under all grid conditions. This paper proposes a high-frequency isolated online UPS system for low power applications. The proposed UPS consists of a single-stage AC-DC converter, boost DC-DC converter, and an inverter. The single-stage AC-DC converter provides galvanic isolation, input power factor correction, and continuous conduction of both input and output current. The low battery bank voltage is stepped up to high dc-link voltage by employing a high voltage gain boost converter, thus allows the reduction of battery bank to only $24 \mathrm{~V}$ parallel connected batteries. Operating batteries in parallel improves the battery performance and resolves the issues related to conventional battery banks that arrange the batteries in series combination. The inverter provides regulated output voltage to the load. A new cascaded slide mode (SM) and proportional-resonant (PR) control for the inverter has been proposed, which regulates the output voltage for both linear and non-linear loads. The controller shows excellent performance during load transients and step changes. Besides, the controller for boost converter and AC-DC converter is presented. Operating principle and experimental results of $1 \mathrm{kVA}$ laboratory setup have been presented for the validation of proposed system.
\end{abstract}

Keywords: uninterruptible power supply (UPS); single-stage AC-DC converter; high-frequency isolation; boost converter; power factor correction

\section{Introduction}

Uninterruptible power supplies (UPSs) deliver clean, conditioned, and reliable power to critical loads such as communication systems, network servers, medical equipment, etc. [1]. Typically, the UPS provides unity power factor, high efficiency, high reliability, low cost, and continuous power supply, irrespective of the grid conditions [2-4].

UPS systems can be categorized as online, offline, and line interactive UPS systems [5]. Among them online UPS systems are the most popular and common configuration, as they provide isolation to the load from the grid and have negligible switching times. A conventional online UPS system consists of a rectifier for PFC, battery bank, and an inverter connected with the load. Grid frequency transformers are normally employed to reduce the battery bank voltage and provide isolation from 
the transients and spikes generated inside the grid. Since the transformer is operating at the grid frequency, it increases the volumetric size and weight of the system significantly.

High-frequency transformer-based UPSs offer an effective solution to the problems mentioned above by reducing the size of the system as well as providing suitable galvanic isolation between the load and grid. Besides, these UPS systems have high power factor correction, zero voltage switching (ZVS) of the chopper and converter stage, and low-cost design [6,7]. However, due to high dc-link voltage, several batteries are connected in a series arrangement, which reduces the reliability of the system.

Table 1. Comparison of high-frequency transformer UPSs for different battery banks.

\begin{tabular}{ccccc}
\hline Reference & Rated Power & Input/Output Voltage & Battery Bank Voltage & Number of Batteries \\
\hline$[8]$ & $300 \mathrm{VA}$ & 120 & 48 & 4 \\
{$[9]$} & $2 \mathrm{kVA}$ & 220 & 108 & 9 \\
{$[10]$} & $150 \mathrm{VA}$ & 120 & 48 & 4 \\
{$[11]$} & $2 \mathrm{kVA}$ & 110 & 180 & 15 \\
{$[12]$} & $3.3 \mathrm{kVA}$ & 220 & 120 & 10 \\
\hline
\end{tabular}

Table 1 shows a comparison of the different high-frequency transformer-based UPS with series connected batteries. Series battery arrangement has major drawbacks and limitations in charging and discharging. A small imbalance in voltages occurs across the battery cells during charging and discharging because the voltages across each cell is not equal. Hence, their performance is different during charging and discharging operations. Severe overheating, low performance, and even destruction may be caused by battery overcharging [13]. Similarly, deep discharge will permanently damage the battery cells [14]. Due to this reason, a small battery bank with batteries operating in parallel improves the performance of the battery bank significantly. The batteries operating in parallel have the following advantages:

(1) The number of batteries is not restricted to the dc-link voltage. The volume, weight, and backup time of the battery bank should be designed according to the specific application.

(2) Cost reduction as no extra voltage balancing circuit is required.

(3) Damaged batteries can be isolated or replaced in the battery bank leaving the sensitive system operation uninterrupted. This is a prime function of UPS systems.

(4) Since the discharging currents of the batteries can be profiled individually, hence the stored energy in the batteries can be utilized more efficiently.

In this paper, a new high-frequency isolated online UPS system configuration is proposed. The proposed UPS consists of a single-stage AC-DC converter, DC-DC boost converter, and H-bridge inverter as shown in Figure 1. The single-stage AC-DC converter provides galvanic isolation, high input power factor, continuous flow of input and output current, with minimum semiconductor devices within the circuit. A high-gain DC-DC converter is introduced to step up the low battery bank voltage to high dc-link voltage in order to feed it to the inverter. This allows the use of a low voltage battery bank in the UPS system. Besides, the converter follows the condition of ZVS and synchronous rectification (SR), which increases the system efficiency. A new cascaded slide mode (SM) and proportional-resonant (PR) controller have been implemented in the inverter control which show good performance with low total harmonics distortion (THD) and high stability for both non-linear and impulsive loads. The volumetric size and cost of the proposed system are comparatively very small as no bulky grid frequency transformer has been used, with a small battery bank, and high efficiency. Hence, the proposed UPS system with its low cost and weight is an excellent choice for low power applications. A $1 \mathrm{kVA}$ laboratory prototype has been constructed to verify the performance of the system. The proposed UPS system shows excellent steady state and dynamic performance. 


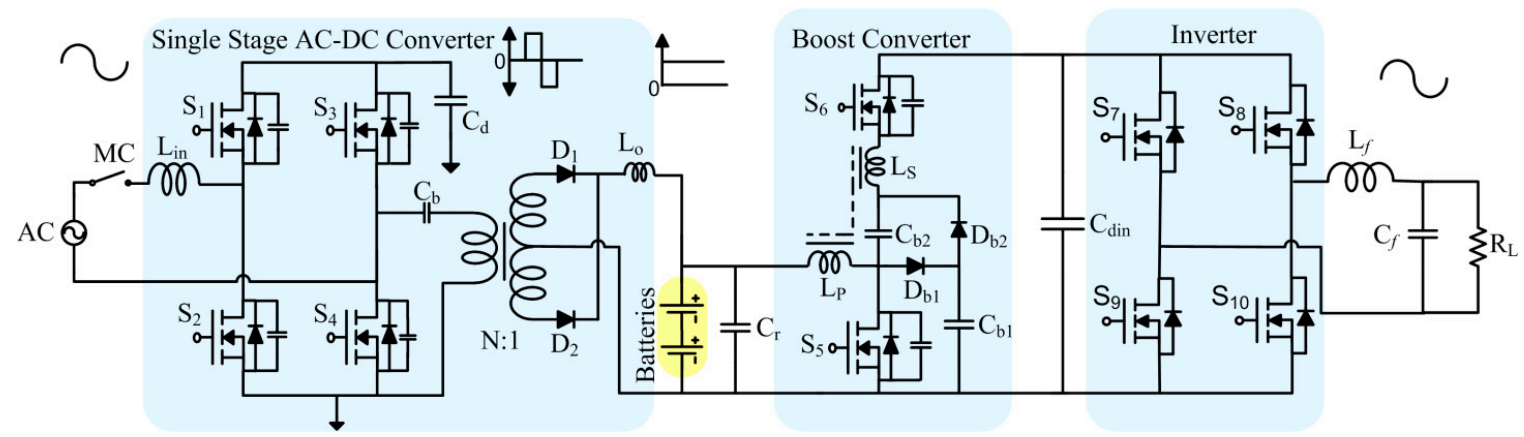

Figure 1. Circuit diagram of the proposed UPS system.

\section{Circuit Description}

The proposed system consists of a single-stage AC-DC converter at the front end, a H-bridge inverter at the back end, and a high-gain boost converter connected with the battery bank of the UPS system. The single-stage AC-DC converter provides rectification, with power factor correction (PFC) as well as high-frequency isolation between the load and grid. The boost converter with high-voltage gain steps up the low battery bank voltage to high dc-link voltage in order to feed it to the inverter. The H-bridge inverter with a new robust control scheme is proposed for operation under the non-linear loading condition and provides the fast transient response during change of modes.

\subsection{Modes of Operation}

The UPS operates in two modes, i.e., grid mode and battery mode, as shown in the Figure 2.

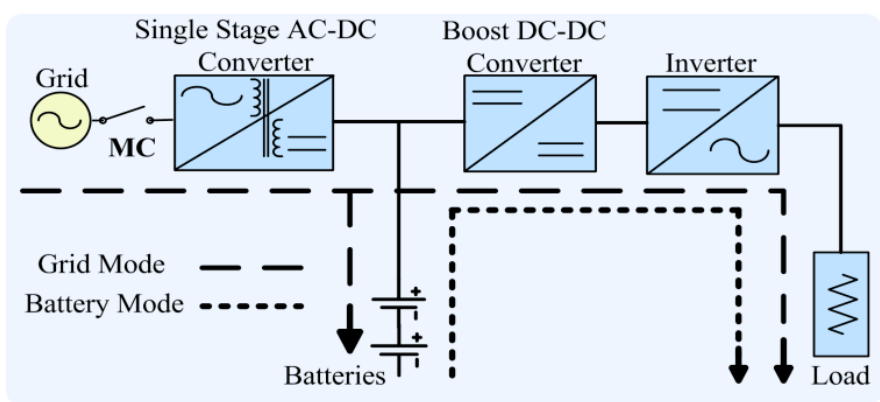

Figure 2. Modes of operation of proposed UPS system.

\subsubsection{Grid Mode}

When the grid voltage is stable and there is no power failure, the UPS system operates in grid mode. The single-stage AC-DC converter regulates the voltage across $\mathrm{C}_{\mathrm{r}}$. Meanwhile; the boost converter steps up battery bank voltage across $C_{r}$ and provides it to the inverter. The inverter provides regulated output voltage to the connected load.

\subsubsection{Battery Mode}

In case of utility power disruption or any voltage sag, the magnetic contactor (MC) is opened, and the single-stage AC-DC converter stops operation. Now the battery supplies power to the load via the boost converter and inverter connected to it. The arrangement of the battery is such that it provides uninterruptible energy to the boost converter at the time of utility line failure. The value of the dc-link capacitor is kept high in order to provide sufficient energy to the inverter during the transition between the power modes. 
A bypass switch has been added in the system to increase the reliability of the system. In case of internal faults in the system or overloading and overheating of the circuit, the bypass switch turns ON and provides a direct path for the power from the utility grid to the connected load [15].

\subsection{AC-DC Converter}

A number of single-stage AC/DC converters have been proposed in the literature [16-21]. Commonly a full bridge diode rectifier has been employed at the front-end of DC/DC converters [22-26], but four diodes operating at line frequency results in high conduction losses, thus dropping the efficiency of the converter. In order to eliminate the aforementioned problems, a bridgeless single-stage PFC AC/DC converter has been implemented in our design.

In [27], a bridgeless single-stage half bridge AC/DC converter has been proposed. It uses only two active switches and two diodes as passive switches to achieve the AC/DC conversion with reduced size and efficient operation. However, the circuit operates in DCM and is not suitable for high power applications. A totem-pole bridgeless PFC connected with high frequency linked DC/DC regulator has been analyzed in [28]. The dc-link capacitor is reduced, which helps in reducing the total cost and size of the system, but the circuit still operates under critical conduction mode of operation.

A single-stage AC/DC converter has been proposed in [29]. The converter operates in continuous condition mode (CCM) and is designed for high power applications, but extra diodes have been used in the circuit which reduces the overall efficiency of the circuit. Also, two separate controllers have been used, which increases the cost and complexity of the circuit.

A new AC-DC converter topology has been introduced, which combines an asymmetrical dc-dc converter with a half bridge PFC rectifier forming a single-stage AC-DC converter. No front end diode rectifier has been used in the circuit. Using the proposed converter, galvanic isolation as well as high efficiency are achieved with only four active switches that reduces the volumetric size of the circuit considerably. Other features of the single-stage converters include continuous conduction of the input and output current, ZVS condition, and excellent input power factor.

The operation of the AC-DC converter in both the positive and negative cycle is symmetrical. Therefore, only the positive cycle is considered in the discussion. Duty cycle D controls the switches $S_{2}$ and $S_{3}$, while duty cycle (1-D) controls switches $S_{1}$ and $S_{4}$. Figure 3 presents the waveforms and operating modes of the AC-DC converter.

\subsubsection{Mode 1}

In this mode, switches $S_{2}$ and $S_{3}$ turn ON under ZVS conditions. The boost inductor $L_{\text {in }}$ is charged by input AC line voltage $V_{\text {in }}$ through the switch $\mathrm{S}_{2}$ and $\mathrm{S}_{3}$. The inductor current is represented by the following equation:

$$
\Delta i_{\text {Lin }}=\frac{1}{L_{\text {in }}}\left(V_{\text {in }}+V_{d}\right) D T_{s}
$$

The blocking capacitor $C_{b}$ is charged by the dc-link capacitor $C_{d}$ through $S_{3}$ and the secondary side of the high-frequency transformer is fed by the energy stored in the magnetizing inductor $L_{m}$. The magnetizing inductor current $i_{L m}$ is represented under the initial condition $i_{L m}(0)$ by Equation (2):

$$
i_{L m}(t)=i_{L m}(0)+\frac{\left(V_{d}-V_{b}\right) D T_{s}}{L_{m}}
$$

The secondary voltage is $V_{s e c 1}=-\frac{N_{s}}{N_{p}} V_{p}=-\frac{N_{s}}{N_{p}}\left(V_{d}-V_{b}\right), V_{s e c 2}=\frac{N_{s}}{N_{p}}\left(V_{d}-V_{b}\right)$. The current through the diode $\mathrm{D}_{1}$ is same as the output filter inductor current, and is given as:

$$
i_{D 1}=i_{L o}(\max )=i_{L o}(0)+\frac{1}{L_{o}}\left(N\left(V_{d}-V_{b}\right)-V_{\text {out }}\right) D T_{S}
$$




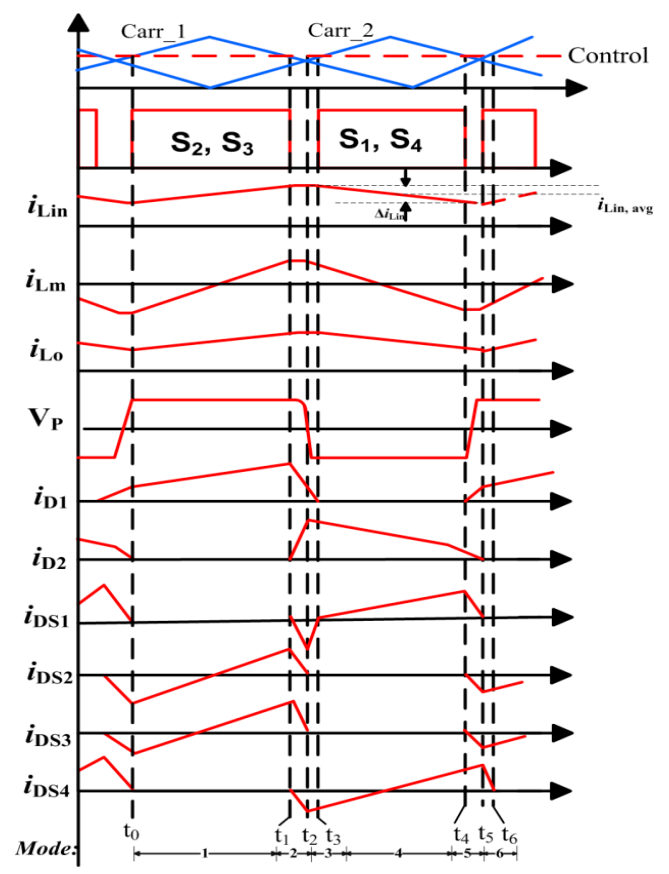

(a)
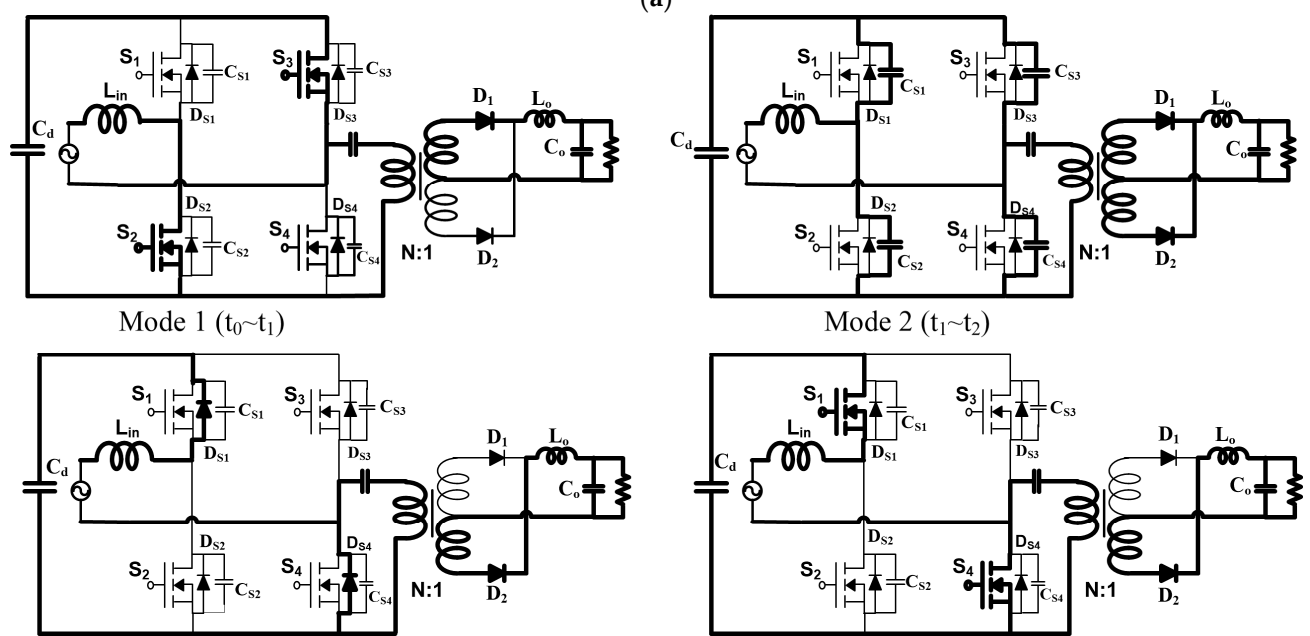

Mode $3\left(\mathrm{t}_{2} \sim \mathrm{t}_{3}\right)$
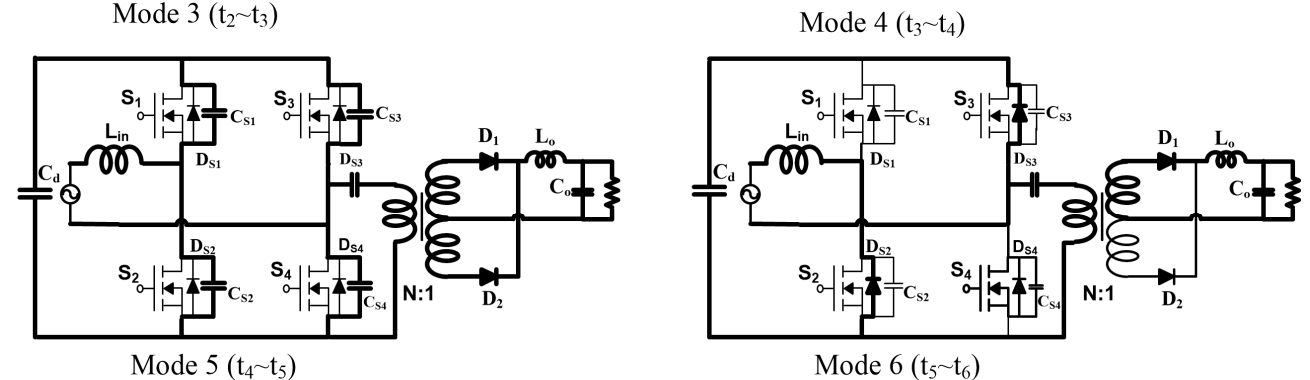

(b)

Figure 3. Single-stage AC-DC Converter: (a) Operation waveforms; (b) Modes of operation during one switching cycle $T_{S}$.

\subsubsection{Mode 2}

Both the switches $S_{2}$ and $S_{3}$ turn OFF during this mode. The parasitic capacitance $C_{S 2}$ is charged and $\mathrm{C}_{\mathrm{S} 1}$ is discharged using inductor current $i_{\text {Lin }}$. Similarly, the capacitance $\mathrm{C}_{\mathrm{S} 3}$ is charged and capacitance $\mathrm{C}_{S 4}$ is discharged by the primary current $i_{P}$ of the transformer. 
The voltage across the switches $S_{1}$ and $S_{4}$ reduces to zero while the voltage across the switch $S_{2}$ and $S_{3}$ increases to $V_{d}$. At the secondary side, the output filter inductor current freewheels through the diodes $\mathrm{D}_{1}$ and $\mathrm{D}_{2}$.

\subsubsection{Mode 3}

In Mode 3 , the dc-link film capacitor $C_{d}$ starts charging by getting energy from the boost inductor and as a result $i_{\text {Lin }}$ starts decreasing. As the voltage across $S_{1}$ reduces to 0 , the body diode $D_{S 1}$ turns ON. Similarly, the blocking capacitor is fed by the magnetizing inductance $L_{m}$ through the body diode $D_{S 4}$. As a result, $i_{L m}$ will induce the flux in the high-frequency transformer secondary winding, and the power will be fed to the output capacitor $C_{r}$.

\subsubsection{Mode 4}

In the start of Mode 4, both the switches $\mathrm{S}_{1}$ and $\mathrm{S}_{4}$ turn ON following the ZVS condition. The DC-link capacitor $C_{d}$ is charged by the stored energy released by the boost inductor $L_{i n}$. The inductor current is given by:

$$
\Delta i_{\text {Lin }}=\frac{1}{L_{\text {in }}}\left(V_{\text {in }}-V_{d}\right)(1-D) T_{S}
$$

The input current flows through $L_{i n}, \mathrm{~S}_{1}, \mathrm{C}_{\mathrm{d}}$, and $\mathrm{S}_{2}$. Similarly, the magnetising current $i_{L m}$ starts decreasing from maximum as represented by the following Equation (5):

$$
i_{L m}(t)=i_{L m}(\max )-\frac{V_{b}}{L_{m}}(1-D) T_{S}
$$

The high-frequency transformer secondary winding feed energy to the output capacitor $D_{2}$. The output filter inductor current $i_{L O}$ is represented by Equation (6):

$$
i_{\text {Lo }}=i_{\text {Lo }}(t)=i_{\text {Lo }}(0)-\frac{1}{L_{o}} N\left(V_{d}-V_{b}\right)(1-D) T_{S}
$$

\subsubsection{Mode 5}

In Mode 5, the switches $S_{1}$ and $S_{4}$ turn OFF. The parasitic capacitor $C_{S 2}$ is discharged and $C_{S 1}$ is charged by both the current from the transformer primary windings and the input inductor $L_{\text {in }}$ to and from $V_{d}$,respectively. Now the voltage across $\mathrm{S}_{2}$ is zero, and the voltage across $\mathrm{S}_{1}$ is $V_{d}$. Similarly, the capacitance $C_{S 4}$ is charged and $C_{S 3}$ is discharged by the primary current $i_{P}$ of the transformer. Thus, the voltage across $\mathrm{S}_{4}$ is $V_{d}$. At the secondary side, the output filter current freewheels through the diode $\mathrm{D}_{1}$ and $\mathrm{D}_{2}$.

\subsubsection{Mode 6}

In Mode 6, the body diode $\mathrm{D}_{\mathrm{S} 2}$ turns $\mathrm{ON}$ because of charging of the inductor. Similarly, the voltage across the switch $\mathrm{S}_{3}$ is zero. This causes the body diode $\mathrm{D}_{\mathrm{S} 3}$ to be turned $\mathrm{ON}$ and the primary current starts flowing through it. In the end of Mode 6, both the $S_{2}$ and $S_{3}$ turn ON under the condition of ZVS.

\subsubsection{Continuous condition mode (CCM) of operation of input inductor}

The proposed AC-DC converter operates in CCM with continuous input current. The minimum inductor for CCM operation can be determined by (7):

$$
L_{i n}>\frac{V_{d}^{2} T_{s} D(1-D)^{2}}{2 P_{o}}
$$


The average current ripple is given by Equation (8):

$$
\Delta i_{L_{i n}}=\frac{\left|V_{m} \sin \omega t\right| D T_{s}}{2 L_{i n}}
$$

The peak current is given by (9):

$$
\left.i_{L_{\text {in }}}\right|_{\text {peak }}=i_{L_{\text {in }}(\text { avg })}+\Delta i_{L_{\text {in }}}=\frac{\left|V_{m} \sin \omega t\right|}{R_{e}}+\frac{\left|V_{m} \sin \omega t\right| D T_{S}}{2 L_{\text {in }}}
$$

where $R_{e}$ is the emulative resistance of the converter. Equation (9) shows that the inductor peak current is not very high because large value of inductor is selected which maintains the continuous conduction.

\subsubsection{Discontinuous conduction mode (DCM) of operation of the input inductor}

If the proposed UPS system is designed for low power applications, the input inductor can be operated in discontinuous conduction mode [30]. The peak boost inductor current follows the line voltage with a fixed duty ratio to supply the output power for a constant output voltage. Suppose the converter is lossless and the duty ratio is fixed, the boost inductor $L_{b}$ should be determined by (10):

$$
L_{i n}<\frac{V_{i n}^{2} D T_{s}}{2 P_{o}}
$$

where $P_{o}$ is the maximum output power. For positive line period, the peak boost inductor current during $T_{S}$ is expressed as (11):

$$
i_{L b, p e a k}=\frac{V_{i n} D T_{S}}{L_{b}}
$$

\subsection{Boost Converter}

A high-gain DC-DC converter has been introduced to obtain high dc-link voltage from the low voltage battery bank [31]. SR has been applied to decrease the conduction losses and force the circuit to operate under ZVS conduction. In order to get the high-voltage gain, coupled inductor is utilized with $L_{P}$ and $L_{S}$ as primary and secondary winding inductance respectively. The characteristic waveform and modes of operation of the DC-DC converter is shown in the Figure 4.

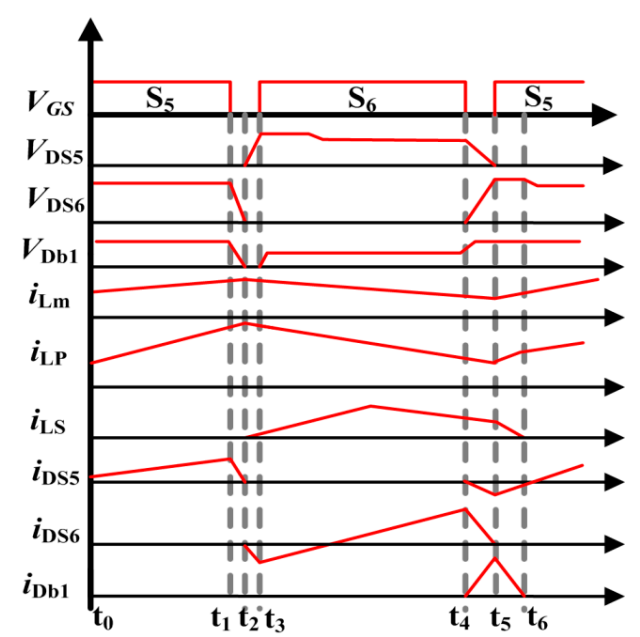

(A) Characteristic waveform of the boost converter

Figure 4. Cont. 


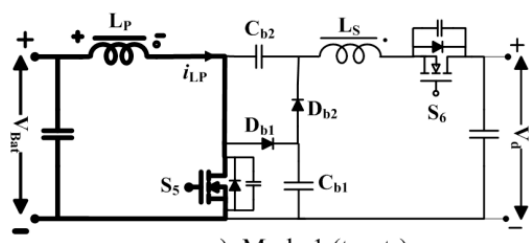

a). Mode $1\left(\mathrm{t}_{0} \sim \mathrm{t}_{1}\right)$

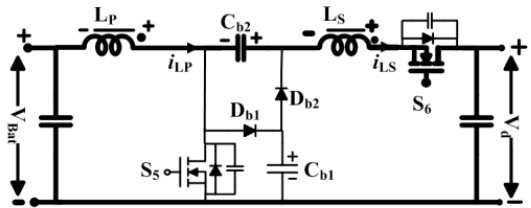

(d) Mode $4\left(\mathrm{t}_{3} \sim \mathrm{t}_{4}\right)$

(e) Mode $5\left(\mathrm{t}_{4} \sim \mathrm{t}_{5}\right)$

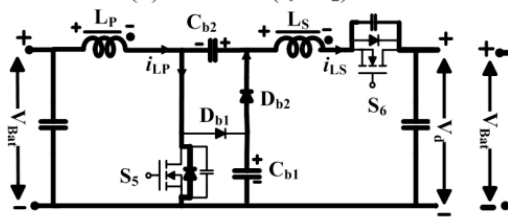

(a) Mode 1; (b) Mode 2; (c) Mode 3; (b). Mode $2\left(t_{1} \sim t_{2}\right)$

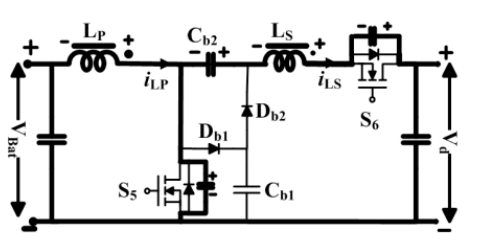

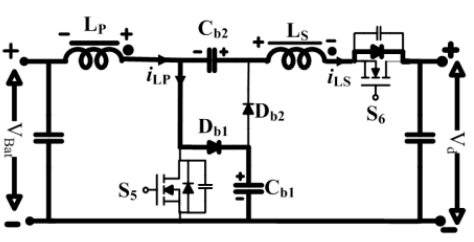

(c) Mode $3\left(\mathrm{t}_{2} \sim \mathrm{t}_{3}\right)$

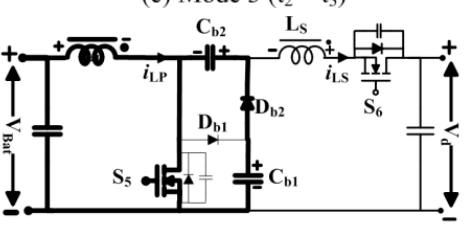

(f) Mode $6\left(\mathrm{t}_{5} \sim \mathrm{t}_{6}\right)$

d) Mode 4; (e) Mode 5; (f) Mode 6

Figure 4. DC-DC boost converter; (A) Characteristic waveform; (B) Topological stages.

\subsubsection{Mode $1\left(t_{0} \sim t_{1}\right)$}

During Mode 1 , the switch $S_{5}$ is $\mathrm{ON}$, while the switch $\mathrm{S}_{6}$ is OFF. Low battery bank voltage is applied at the input of the DC-DC boost converter. Capacitor $\mathrm{C}_{\mathrm{b} 2}$ remains charged before Mode 1 and the magnetizing current $i_{L m}$ of the coupled inductor increases linearly, as shown in the Figure 5.

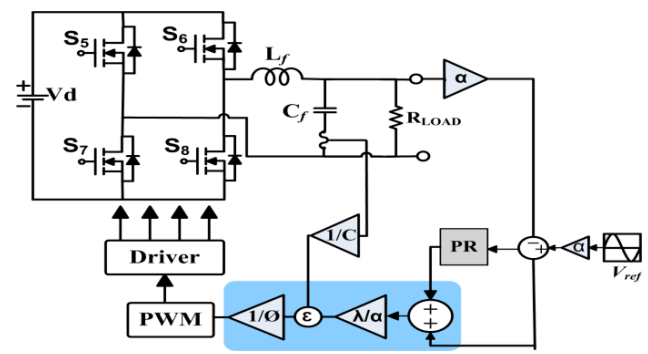

(a)

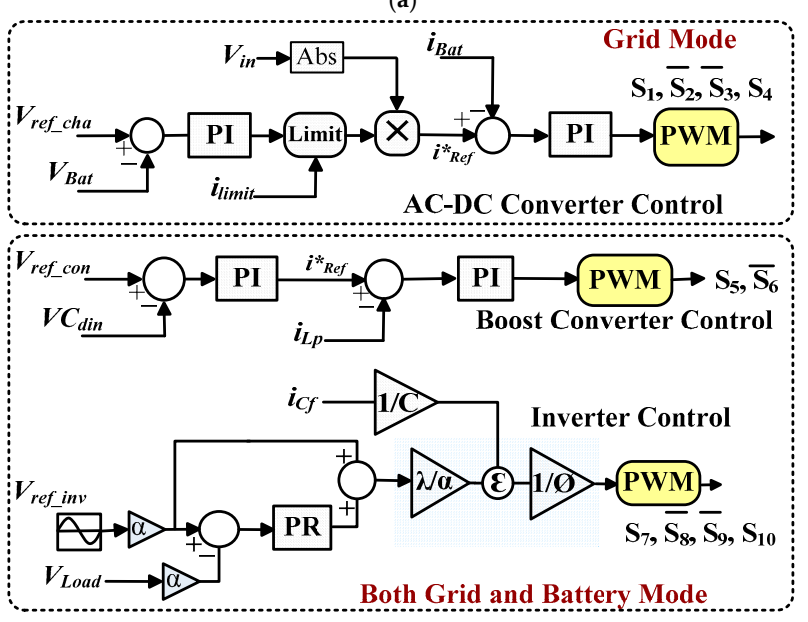

(b)

Figure 5. Proposed control scheme: (a) Inverter control; (b) Control circuit UPS system.

Applying KVL, we get:

$$
V_{L}=V_{L p}=V_{L S} / N
$$

The voltage across the primary winding can be find using voltage second balance:

$$
V_{L P}(1-D)=V_{L} D
$$




\subsubsection{Mode $2\left(t_{1} \sim t_{2}\right)$}

The switch $\mathrm{S}_{5}$ turns OFF in Mode 2 . The primary current $i_{L P}$ charges the parasitic capacitance across the switch $S_{5}$ and the secondary current $i_{L S}$ discharges the parasitic capacitance across switch $\mathrm{S}_{6}$. When the voltage across switch $S_{5}$ equals to the capacitor voltage $V_{\mathrm{Cb} 1}$, this mode finishes.

\subsubsection{Mode $3\left(t_{2} \sim t_{3}\right)$}

Since the switch $\mathrm{S}_{5}$ is $\mathrm{OFF}$, the primary current $i_{L P}$ decreases due to leakage inductance. However, the secondary current $i_{L S}$ increases, which results in the turning $\mathrm{ON}$ of the body diode of switch $S_{6}$. As the voltage across the switch $S_{5}$ is higher than capacitor $C_{b 1}$, it charges $C_{b 1}$ through diode $D_{b 1}$. Hence, the voltage stress across the switch $S_{5}$ has been reduced. $V_{C b 1}$ is the voltage across the capacitor $\mathrm{C}_{\mathrm{b} 1}$, and is represented by Equation (14):

$$
V_{\mathrm{Cb} 1}=V_{L}+V_{L P}
$$

Using (13):

$$
V_{\mathrm{Cb} 1}=V_{L} /(1-D)
$$

\subsubsection{Mode $4\left(\mathrm{t}_{3} \sim \mathrm{t}_{4}\right)$}

In Mode 4, the switch $\mathrm{S}_{6}$ turns ON under ZVS conditions. Both the windings of the coupled inductor and the capacitor $C_{b 2}$ series connected together transfer maximum energy to the output capacitor $C_{d i n}$ of the converter. The $i_{L S}$ starts increasing until it reaches the $i_{L P}$, then it follows the $i_{L P}$ till the end of the Mode 4 . Thus, the energy stored in both the windings of the coupled inductor discharges across the high voltage side of the circuit. $D_{b 1}$ and $D_{b 2}$ are reverse biased during this mode. Applying voltage second balance, we get Equation (16):

$$
\begin{gathered}
V_{H}=V_{L}+V_{L S}+V_{\mathrm{Cb} 2}+V_{L p} \\
V_{H}=V_{L}+V_{\mathrm{Cb} 2}+(N+1) V_{L P}
\end{gathered}
$$

\subsubsection{Mode $5\left(t_{4} \sim t_{5}\right)$}

During this mode, the switch $\mathrm{S}_{6}$ turns OFF. The current $i_{L S}$ charges the parasitic capacitance of the switch $S_{6}$. Capacitor $C_{b 2}$ is charged by the capacitor $C_{b 1}$ through the diode $D_{b 2}$ :

$$
V_{\mathrm{Cb} 2}=V_{\mathrm{Cb} 1}=V_{L} /(1-D)
$$

By substituting (13) and (18) into (17), presents the voltage gain of the converter:

$$
\begin{gathered}
V_{H}=V_{L}+V_{L} /(1-D)+(N+1) D /(1-D) V_{L} \\
G_{\text {boost }}=V_{H} / V_{L}=(2+N D) /(1-D)
\end{gathered}
$$

The body diode of the switch $S_{5}$ turns $\mathrm{ON}$ because of the polarities of capacitor $\mathrm{C}_{\mathrm{b} 2}$ and inductor $L_{P}$.

\subsubsection{Mode $6\left(\mathrm{t}_{5} \sim \mathrm{t}_{6}\right)$}

During this mode, the switch $\mathrm{S}_{5}$ turns to ON state under ZVS conditions. Since no current is derived by switch $S_{5}$ from the clamped circuit, thus the switching losses remains low due to ZVS, results in increasing the efficiency of the converter. Mode 6 finishes at the point when both the $V_{\mathrm{Cb} 1}$ and $V_{\mathrm{Cb} 2}$ become equal. The turn ratio $N=4$ is selected to satisfy the $G_{b o o s t}$ gain in order to step up the battery bank voltage to required dc-link of inverter. 


\section{Control Strategy}

The control schemes for regulating different parts of the proposed UPS, in different modes of operation are shown in Figure 5. The control scheme for inverter and boost converter keeps operating in both the normal and battery powered mode. On the other hand, for a single-stage converter the control scheme operates only in normal mode of operation for charging the battery as well as supplying power to the boost converter.

\subsection{Inverter Control}

A conventional full bridge voltage source inverter has been used to perform DC to AC conversion. SM control is famous for its excellent performance against non-linear loading conditions. SMC is also robust in operation and easy to implement for a full bridge inverter. In order to control the output voltage of the inverter, cascaded control algorithm of SMC and PR has been proposed for the control of inverter. The inner current loop is controlled by the SM control while the outer voltage loop is controlled by the PR control. Smoothed control law in narrow boundary layer has been used to eliminate the phenomena of chattering SMC. The smoothed control law is applied to the pulse width modulator that results in the fixed switching frequency of the inverter. Thus, the proposed controller adopted the characteristic of both SMC and PR control.

The circuit diagram of a single phase inverter with LC filter and proposed controller for non-linear load is shown in Figure $5 \mathrm{a}$, where $V_{d}$ is the applied DC-link voltage, $V_{\text {out }}$ the filter capacitor $C_{f}$ output voltage. $i_{L f}$ is the inductor $L_{f}$ current and $i_{o}$ the output current through the load $R$, given by $i_{o}=V_{\text {out }} / R_{\text {Load }}$. The state equations of the inverter are given as:

$$
\frac{d}{d t}\left[\begin{array}{c}
V_{\text {out }} \\
i_{L f}
\end{array}\right]=\left[\begin{array}{cc}
0 & 1 / C_{f} \\
1 / L_{f} & 0
\end{array}\right]\left[\begin{array}{c}
V_{\text {out }} \\
i_{L f}
\end{array}\right]+\left[\begin{array}{c}
0 \\
V_{d} / L_{f}
\end{array}\right] u+\left[\begin{array}{c}
0 \\
i_{o} / C_{f}
\end{array}\right]
$$

where $u=$ Control input $=\{-1,0,+1\}$.

In order to implement the sliding mode control, the voltage error $x_{1}$, and its derivative $x_{2}=\dot{x}_{1}$ need to be find:

$$
\begin{gathered}
x_{1}=V_{\text {out }}-V_{\text {ref }} \\
x_{2}=\dot{x}_{1}=\dot{V}_{\text {out }}-\dot{V}_{r e f}=i_{C f} / c_{f}-\dot{V}_{r e f}
\end{gathered}
$$

where $V_{r e f}=V_{m} \sin (\omega t)$. Consider the slide surface equation:

$$
S=\lambda x_{1}+x_{2}
$$

Now to apply the sliding control law to the inverter, putting the value of $x_{1}$ and $x_{2}$ :

$$
\begin{gathered}
S=\lambda\left(V_{\text {out }}-V_{\text {ref }}\right)+\frac{i_{C f}}{C_{f}}-\dot{V}_{\text {ref }} \\
S=\lambda\left(V_{\text {out }}-V_{\text {ref }}\right)+\frac{1}{C_{f}}\left(i_{C f}-i_{r e f}\right)
\end{gathered}
$$

The sliding mode controller has the common inherent property of chattering. Chattering affects the control accuracy and reduces the efficiency of the circuit. In order to overcome the chattering, a smoothed SM control has been implemented. This can be achieved by smoothing out the control discontinuity in a thin boundary layer neighboring the sliding surface:

$$
B(t)=\{x,|S(x ; t)| \leq \varnothing\} \varnothing>0
$$


where $\varnothing$ is the boundary layer thickness and $\varepsilon=\frac{\varnothing}{\lambda}$ is the boundary layer width. Hence, interpolating $S$ inside $B(t)$, for instance, and replacing $S$ by an expression $S / \varnothing$, Equation (26) will be:

$$
\frac{S(x)}{\varnothing}=\frac{\lambda}{\varnothing}\left[V_{\text {out }}-V_{\text {ref }}\right]+\frac{1}{C_{f} \varnothing}\left[i_{C f}-i_{r e f}\right]
$$

The smoothing control discontinuity assigns a low pass filter structure to the local dynamics thus eliminating chattering. The control law needs to be tuned very precisely in order to achieve a trade-off between the tracking precision and robustness to the uncontrolled dynamics. Hence, the final equation for the control of the inverter can be derived by combining the proportional resonant control and SM control for the current loop:

$$
\frac{S(x)}{\varnothing}=\frac{1}{C \varnothing}\left[i_{C}-i_{r e f}\right]+\frac{\lambda}{\varnothing}\left[K_{p}\left(V_{\text {out }}-V_{\text {ref }}\right)+k_{i}\left(\frac{2 s}{s^{2}+2 \omega_{c} s+\omega_{o}^{2}}\right)\left(V_{\text {out }}-V_{\text {ref }}\right)\right]
$$

Thus Equation (29) shows the dynamic behavior in both SM and PR compensator control. The error in the voltage loop is compensated by the appropriate PR parameters, thus, the output voltage is compelled to follow the reference AC voltage leading to system stability while the SMC drives the system to the zero sliding surface with maximum stability. Since the capacitor error current contains the ripples from the inductor, the current peak may reach high values, so $\varnothing$ should be carefully assigned a value in order to compensate the slope from the high current ripple of the capacitor. Hence, the PR controller eliminates the steady-state error at resonant frequency or harmonic at that frequency. The response time of the system $\lambda$ determines the dynamics and robustness of the system. It is clear from Equation (29), that a smaller value of $\lambda$ leads to a slow response time, while higher $\lambda$ values though increase the response time, but take a longer time to reach the sliding surface. Thus the optimal value for $\lambda$ is equal to the switching frequency of the inverter.

According to [32], the slope of the carrier wave is $4 V_{m} \times f_{S}$, where $V_{m}$ is the magnitude and $f_{S}$ is the frequency of carrier wave. The slope of the error signal to the modulator is given by $V_{D C} / 4 L C \varnothing$. According to the limitation of the pulse width modulator, slope of error signal < slope of the carrier signal:

$$
4 V_{m} \times f_{S}<V_{D C} / 4 L C \varnothing
$$

Thus, the minimum value of $\varnothing$ can be calculated using (30):

$$
\varnothing \cong \frac{10 V_{D C}}{16 L C V_{m} f_{S}}
$$

Table 2 shows the comparison of the proposed control scheme with the SM control and other common controllers. The proposed controller shows an improvement in terms of reducing the THD and transient response $\left(T_{S}\right)$ with robust control of the inverter.

Table 2. Comparison of different control methods.

\begin{tabular}{cccccc}
\hline Parameters & $\begin{array}{c}\text { Model Predictive } \\
\text { Control [33] }\end{array}$ & $\begin{array}{c}\text { SPWM } \\
\text { Control [34] }\end{array}$ & $\begin{array}{c}\text { Rotating } \\
\text { SMC [35] }\end{array}$ & $\begin{array}{c}\text { Fix-Freq } \\
\text { SMC [36] }\end{array}$ & Proposed Work \\
\hline$V_{D C}$ & 529 & 405 & 300 & 360 & 350 \\
$V_{R M S}$ & 150 & 220 & 200 & 220 & 220 \\
$C_{f}(\mathrm{uF})$ & 40 & 202 & 100 & 9.4 & 6.6 \\
$L_{f}(\mathrm{mH})$ & 2.4 & 0.03 & 0.250 & 0.357 & 0.84 \\
$T H D(\mathrm{~L})$ & $2.85 \%$ & $1.11 \%$ & - & $1.1 \%$ & $0.45 \%$ \\
$T H D(\mathrm{NL})$ & $3.8 \%$ & $3.8 \%$ & $2.66 \%$ & $1.7 \%$ & $1.25 \%$ \\
$T_{S}(\mathrm{~ms})$ & 50 & 60 & - & 0.5 & 0.3 \\
\hline
\end{tabular}




\subsection{Battery Charger Control}

The AC-DC converter of the UPS system acts as a battery charger as shown in Figure 5. In this control scheme, the faster inner current loop regulates the inductor current so that its average value during each period follows the rectified input voltage. The slower outer voltage loop maintains the battery voltage close to reference voltage and generates the control signal for the current loop. The steady state analysis of the AC-DC converter shows stable performance during grid mode. The state space equations of the rectifier are derived as:

$$
\begin{gathered}
\frac{d i_{L}}{d t}=\frac{V_{\text {in }}}{L_{\text {in }}} D+\frac{\left(V_{\text {in }}-V_{d}\right)}{L_{\text {in }}}(1-D) \\
\frac{d v_{d}}{d t}=-\frac{V_{d}}{R C_{d}} D+\left(\frac{i_{L}}{C_{d}}-\frac{V_{d}}{R C_{d}}\right)(1-D)
\end{gathered}
$$

Assuming the current loop has high bandwidth as compared to the voltage loop, and dc-link capacitor $C_{d}$ is large enough to give approximately constant voltage i.e., $d v_{d} / d t=0$. With $\hat{V}_{\text {in }}=0$, the small signal control $\hat{d}$ to input current $\hat{i}_{L}$ transfer function $G_{i_{L} d}(s)$ of the inner current loop is give by:

$$
G_{i_{L} d}(s)=\frac{\hat{i}_{L}}{\hat{d}}=\frac{V_{d}}{s\left(L_{i n}\right)}
$$

The stability of the current loop depends on the current loop gain, hence a suitable proportional-integral (PI) controller $G_{i}(s)=k_{p i}+\frac{k_{i i}}{s}$, is used for compensating the current loop. The Bode plot of the current loop gain $T_{i}=G_{i_{L} d}(s) \cdot G_{i}(s)$ is obtained considering the circuit parameters shown in Table 4 . The values of the proportional gain $K_{p i}$ and integral gain $K_{i i}$ are selected as 2.3 and 1200, respectively, for the stable operation of the current loop. Figure 6a presents the Bode plot of the current loop gain with phase margin of $89^{\circ}$ and stable operation of the rectifier.

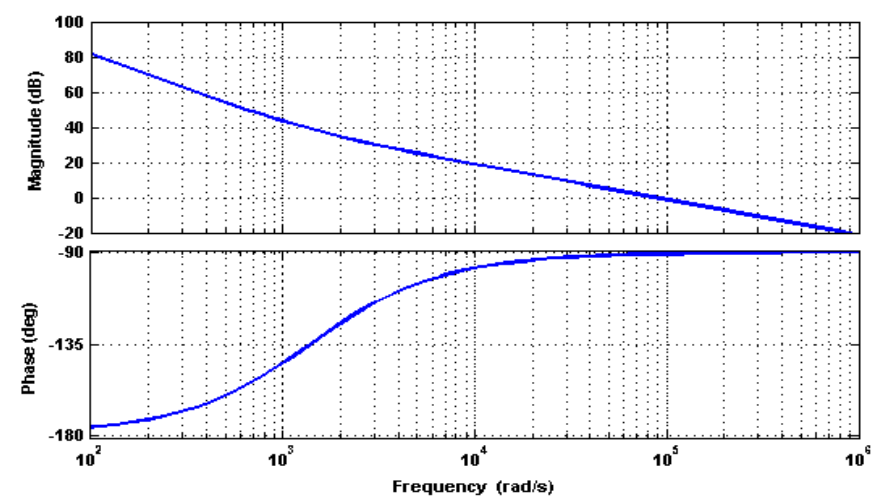

(a)

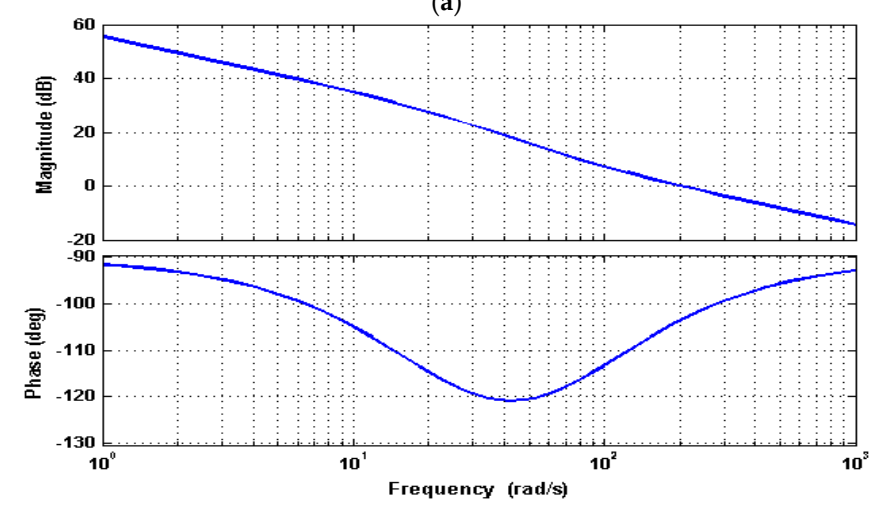

(b)

Figure 6. Bode response of rectifier; (a) Current loop gain; (b) Voltage loop gain. 
The same approach is used to compensate the voltage loop of the average current control scheme. $\hat{v}_{\mathcal{C}}$ is the reference current for the current loop. Assuming constant input voltage, the small signal control $\hat{v}_{c}$ to output transfer function $G_{V_{d} V_{c}}(s)$ of the voltage loop is derived as:

$$
G_{V_{d} V_{c}}(s)=\frac{\hat{v}_{d}}{\hat{v}_{c}}=\frac{V_{i n} R}{2 V_{d}(s C R+2)}
$$

In order to force the output voltage to follow the reference voltage $V_{\text {Ref }}$, a proportional-integral (PI) compensator has been employed. Combining the power stage with the PI controller $G_{v}(s)=k_{p v}+\frac{k_{i v}}{s}$ provides the overall loop gain.

$T_{v}=G_{v} \cdot G_{V_{d} V_{c}}(s)$ of the voltage loop. The values of $K_{p v}$ and $K_{i v}$ in voltage loop are selected as 1.2 and 13, respectively. The stability of the voltage loop can be analyzed using the Bode plot obtained by considering the parameters from Table 4, as shown in Figure 6b. The system shows good stability with a positive phase margin.

In charging mode, the controller operates as constant current mode CC or constant voltage mode $\mathrm{CV}$ depending on the battery voltage as shown in the Figure $5 \mathrm{~b}$. In current loop, the battery input current $i_{\text {Bat }}$ is forced to follow the reference current $i_{\text {Ref }}$ using a PI compensator in (36):

$$
i^{*}=K_{p}\left(i_{R e f}-i_{\text {Bat }}\right)+K_{i} \int\left(i_{R e f}-i_{\text {Bat }}\right) d t
$$

Similarly, the battery voltage is regulated by the voltage loop using the PI compensator that forces the output battery voltage $V_{\text {Bat }}$ to follow the reference voltage $V_{\text {ref. }}$. The current limiter is introduced to limit the maximum charging current of the battery. If the $i_{\text {ref }}$ is greater than $i_{\text {limit }}$, the battery is charged at constant current (CC Mode), in contrast if the $i_{\text {ref }}$ is less than $i_{\text {limit }}$, the battery is charged at constant voltage (CV mode).

\subsection{Boost Converter Control}

The steady state analysis of the boost converter is performed using average state variable method [30]. The state space equation for the converter with coupled inductor is derived as:

$$
\begin{gathered}
\frac{d i_{P}}{d t}=\frac{V_{\text {Bat }}}{d t} D+\frac{\left(V_{\text {Bat }}-V_{d}\right)}{L_{m}(N+1)}(1-D) \\
\frac{d V_{o}}{d t}=\frac{i_{p}}{C(N+1)}(1-D)-\frac{V_{o}}{R C}
\end{gathered}
$$

Now we perturb the system and consider only the dynamic terms and eliminate the product of the $\mathrm{AC}$ terms because of very small value. The final equation after Laplace transform is:

$$
\begin{gathered}
s \hat{v}_{o}=\hat{i}_{P}\left(\frac{1-D}{C(N+1)}\right)-\frac{\hat{v}_{d}}{R C}-\frac{I_{P}}{C(N+1)} \hat{d} \\
s \hat{i}_{P}=\hat{v}_{B a t}\left(\frac{D}{L_{m}}+\frac{1-D}{L_{m}(N+1)}\right)-\hat{v}_{d}\left(\frac{1-D}{L_{m}(N+1)}\right)+\hat{d}\left(\frac{V_{B a t}}{L_{m}}-\frac{V_{B a t}+V_{d}}{L_{m}(N+1)}\right)
\end{gathered}
$$

Solving (37) and (38) gives the transfer function of the converter:

$$
\frac{\hat{v}_{o}}{\hat{d}}=\frac{s\left(-\frac{I_{P}}{C(N+1)}\right)+\frac{(1-D)}{C(N+1)}\left(\frac{V_{B a t}}{L_{m}}+\frac{V_{d}-V_{B a t}}{L_{m}(N+1)}\right)}{s^{2}+s \frac{1}{R C}+\frac{(1-D)^{2}}{(1+N)^{2} L_{m} C}}
$$


Considering the gain due to clamp capacitor $\mathrm{C}_{\mathrm{b} 2}$, the transfer equation is given by:

$$
\frac{\hat{v}_{o}}{\hat{d}}=\frac{s\left(-\frac{I_{P}}{C(N+1)}\right)+\frac{(1-D)}{C(N+1)}\left(\frac{V_{B a t}}{L_{m}}+\frac{V_{d}-V_{B a t}(D / 1-D)}{L_{m}(N+1)}\right)}{s^{2}+s \frac{1}{R C}+\frac{(1-D)^{2}}{(1+N)^{2} L_{m} C}}
$$

The stability of the converter can be analyzed using the Bode plot shown in Figure 7. The system shows good stability with a positive phase margin and it has no right half plane poles. It is easy to achieve high crossover frequencies by adjusting a suitable gain of the compensators as the phase never reaches -180 . The voltage across DC-link capacitor $C_{d i n}$ is regulated by using a suitable voltage compensator [37]. The PI compensator is used to track the DC-link voltage $V_{d}$ to follow the reference voltage, as shown in Figure 7.

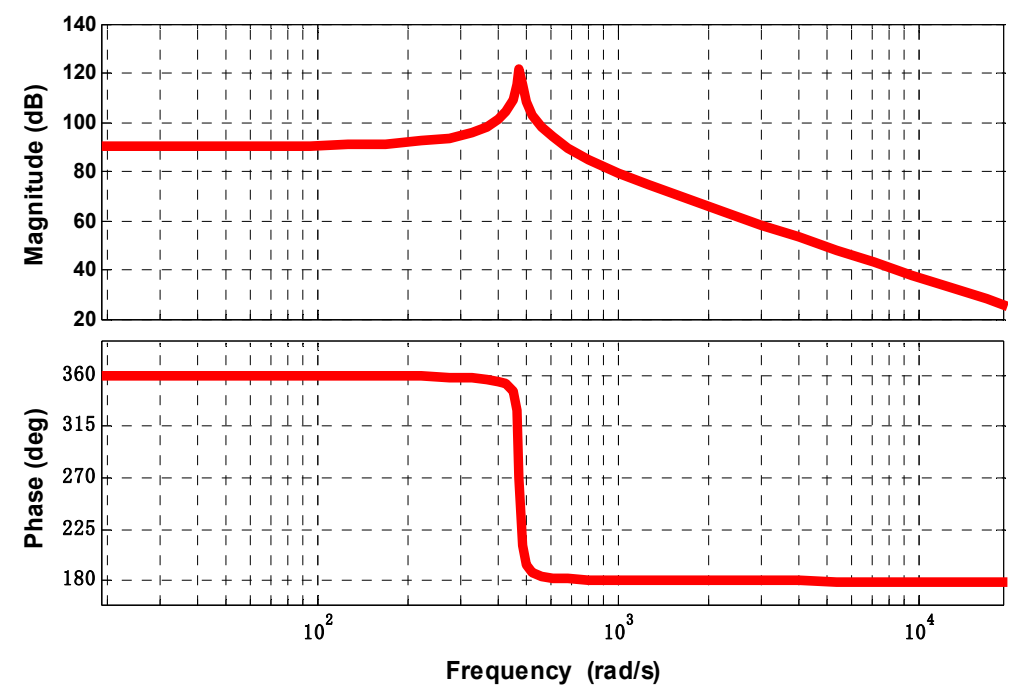

Figure 7. Bode plot of the boost converter.

\section{Experimental Results}

In order to validate the performance of our UPS system, a laboratory prototype has been implemented. The specifications of the UPS are shown in Table 3. The control scheme for the single-stage converter, boost converter, and H-bridge inverter has been implemented using DSP TMS320F28335. The design parameters of the single-stage converter and DC-DC converter are shown in Tables 4 and 5, respectively. The backup storage system consists of two batteries (each battery is $24 \mathrm{~V} / 35 \mathrm{Ah}$ ), or parallel batteries, depending upon the backup time for the connected load.

Table 3. Specifications of the proposed UPS system.

\begin{tabular}{ccc}
\hline Parameters & Symbol & Value \\
\hline Input Voltage & $V_{\text {in }}$ & $220 \mathrm{~V}$ \\
Output Voltage & $V_{\text {out }}$ & $220 \mathrm{~V}$ \\
Grid Frequency & $f_{r}$ & $50 \mathrm{~Hz}$ \\
Output Frequency & $f_{o}$ & $50 \mathrm{~Hz}$ \\
Number of Batteries & $V_{b}$ & 2 Parallel connected (24 V/35 Ah) \\
Maximum Output Power & $P_{o, \max }$ & $1 \mathrm{kVA}$ \\
DC-link Voltage & $V_{d}$ & $360 \mathrm{~V}$ \\
\hline
\end{tabular}


Table 4. Design parameters of the single-stage AC-DC converter.

\begin{tabular}{ccc}
\hline Parameters & Symbol & Value \\
\hline Input Inductor & $L_{i n}$ & $1.2 \mathrm{mH}$ \\
Switches & $\mathrm{S}_{1} \sim \mathrm{S}_{4}$ & SPP11N60C3 \\
Fast Diodes & $\mathrm{D}_{1}, \mathrm{D}_{2}$ & C3D10060A \\
Switching frequency & $f_{s}$ & $50,000 \mathrm{~Hz}$ \\
H. F Transformer & $T$ & $L_{m}=600 \mathrm{uH}, \mathrm{TDK}$ core PQ-40/40 \\
DC-Link Capacitor & $C_{d}$ & $1900 \mathrm{uF}$ \\
\hline
\end{tabular}

Table 5. Specifications of the boost DC-DC converter.

\begin{tabular}{ccc}
\hline Parameters & Symbol & Value \\
\hline DC-Link Voltage & $V_{d_{I} I N V}$ & $360 \mathrm{~V}$ \\
Battery Bank Voltage & $V_{b}$ & $24 \mathrm{~V}$ \\
Switching Frequency & $f_{s}$ & $30,000 \mathrm{~Hz}$ \\
Coupled Inductor & $L_{P}, L_{S}$ & Turns ratio $N=4 ;$ Magnetizing Inductor $L_{m}=107 \mathrm{uH} ;$ PQ-5050 core \\
Capacitor & $C_{\mathrm{b} 1}, \mathrm{C}_{\mathrm{b} 2}$ & $C_{\mathrm{b} 1}, \mathrm{C}_{\mathrm{b} 2}=2 \times 2.2 \mathrm{uF}$ (ceramic), $\mathrm{C}_{\mathrm{d}}=1900 \mathrm{uF}$ \\
Switches & $\mathrm{S}_{5}, \mathrm{~S}_{6}$ & IPW60R045CP MOSFET (Infineon Technologies, Santa Clara, CA USA) \\
Diodes & $\mathrm{D}_{\mathrm{b} 1, \mathrm{D}_{\mathrm{b} 2}}$ & Ultrafast Recovery diode UF5408 \\
\hline
\end{tabular}

The utility input voltage and current waveform in normal mode of operation is shown in Figure 8a. The input is sinusoidal, with unity power factor and THD less than 5\%. The output voltage and current waveform during linear loads and non-linear load are shown in Figure 8b,c. The waveform is sinusoidal for linear loads with THD less than $1 \%$. For a non-linear load designed according to the standard of IEC62040-3, the THD is $1.25 \%$ [38].

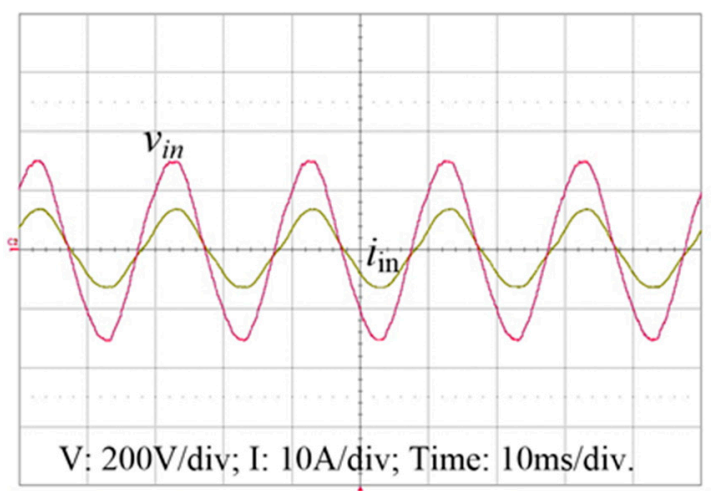

(a)

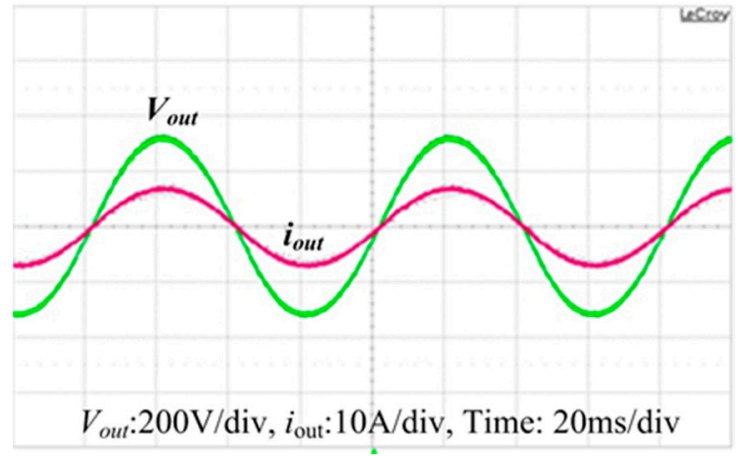

(b)

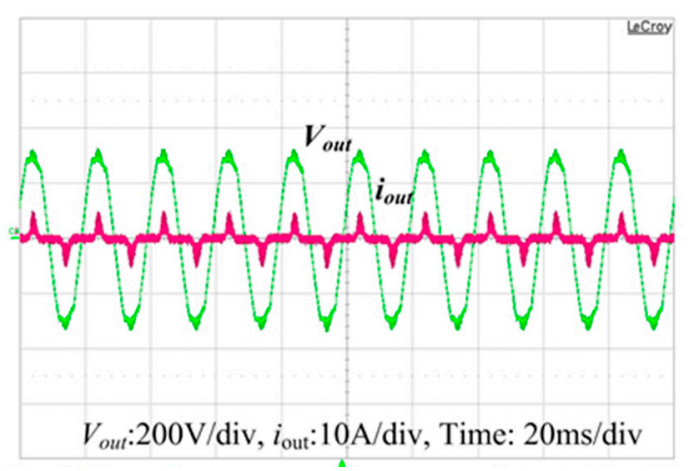

(c)

Figure 8. Experimental waveform of the input output voltage and current of the UPS system. (a) Input line voltage and current; (b) Inverter with linear Load; (c) Inverter with Non-linear load. 
Figure 9a shows the drain to source voltage and current of the switches $S_{3}$ and $S_{4}$. Both the switches are operating under the condition of ZVS. Figure $9 b$ shows the drain to source voltage of the switches $\mathrm{S}_{5}$ and $\mathrm{S}_{6}$ of the boost converter. Both switches are operating under the condition of ZVS. Also the voltage stress across the switches is also limited. When the grid power is interrupted, the system switches from grid mode to battery mode. The rectifier is no longer in operation and the boost converter provides regulated dc-link voltage.
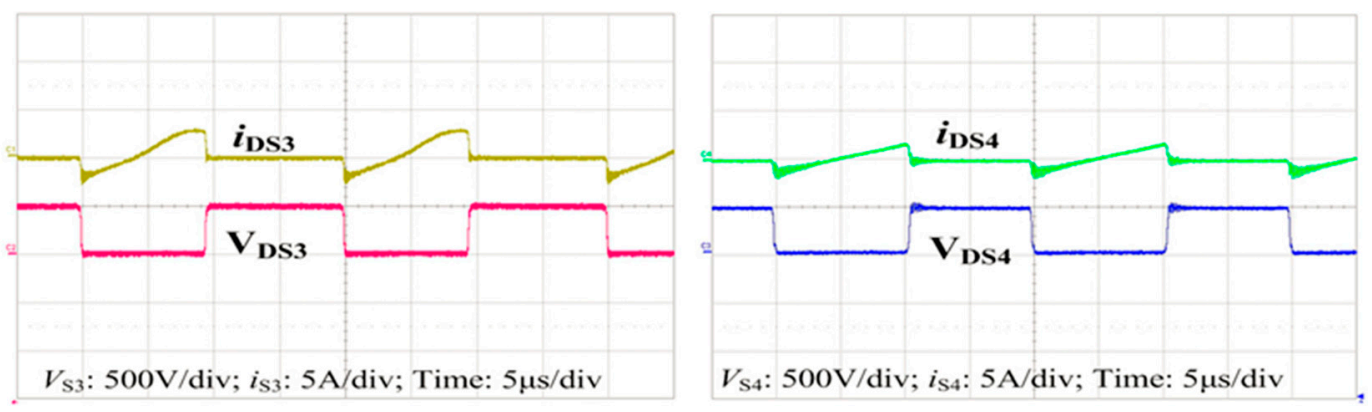

$(\mathbf{a})$
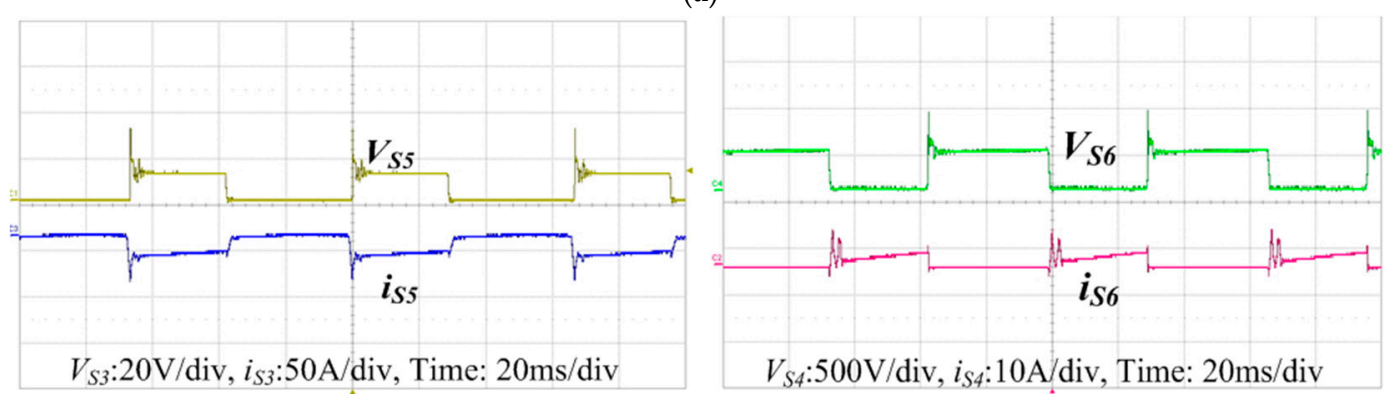

(b)

Figure 9. Drain to source voltage and current of the switches. (a) $S_{3}$ and $S_{4}$ of single-stage AC-DC Converter; (b) $\mathrm{S}_{5}$ and $\mathrm{S}_{6}$ of boost DC-DC converter.

The transient effect in the output voltage is very small and the UPS system provides uninterruptible power to the load as shown in Figure 10a. Similarly, the transition from battery mode back to grid mode upon the restoration of the grid power is shown in Figure 10b. There is a small transient at the turning ON point of the AC-DC converter. This transient is due to the inductor which remains charged due to previous grid mode of operation. However the small transient can be controlled by a suitable snubber circuit. Figure 10 also shows that the inverter keeps operating in both the grid and battery powered mode of operation and the load is getting power without any interruption. Figure 11 shows a photograph of our laboratory prototype. Figure 12 shows the efficiency graph with maximum efficiency of $95 \%$ during battery mode and $91 \%$ during grid mode of operation. Thus utilizing soft switching in boost converter reduces the switch losses and increases the efficiency of the system. The efficiency in battery mode is high as compared to grid mode because less number of power stages are operation during this mode. Table 6 shows a comparison of the different high-frequency transformer isolated UPS systems. The proposed UPS shows a distinct improvement in terms of increasing the efficiency, reducing the size of the battery bank, and decreasing the volumetric size and weight of the system. 


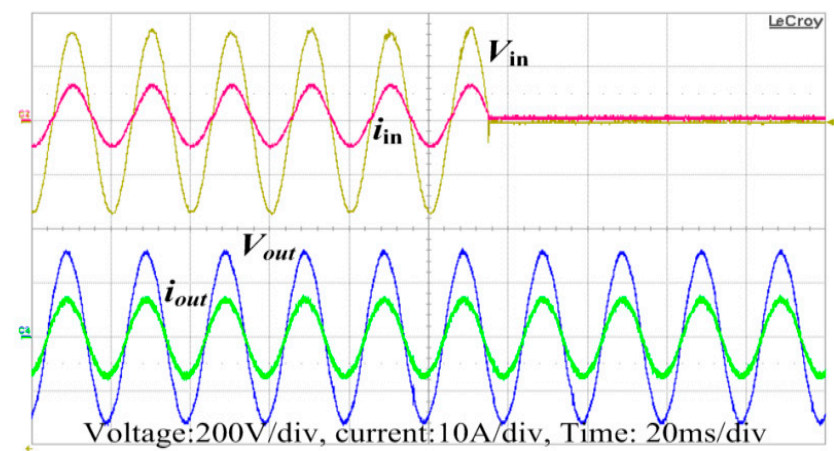

(a)

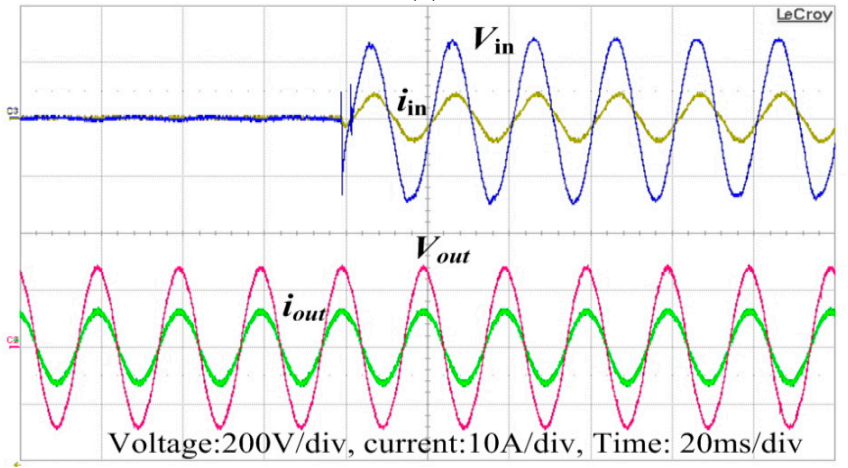

(b)

Figure 10. Transition between two modes of operation, Input voltage $V_{\text {in }}$ and current $I_{\text {in }}$, Output voltage $V_{\text {out }}$ and current $I_{\text {out }}$. (a) Grid to battery mode and (b) Battery mode to grid mode.

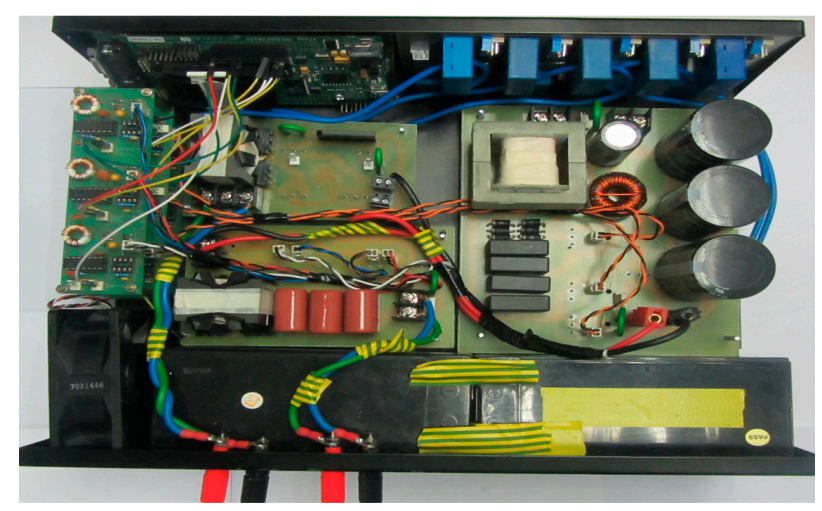

Figure 11. Laboratory prototype.

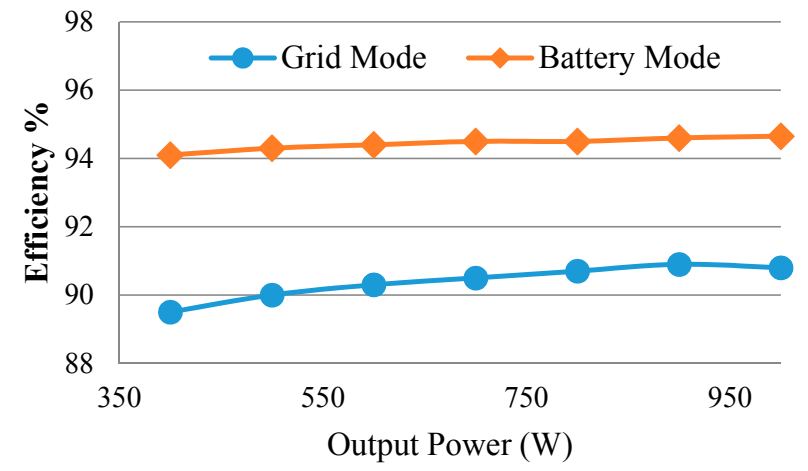

Figure 12. Efficiency graph of UPS in grid and battery mode. 
Table 6. Comparison of the proposed system.

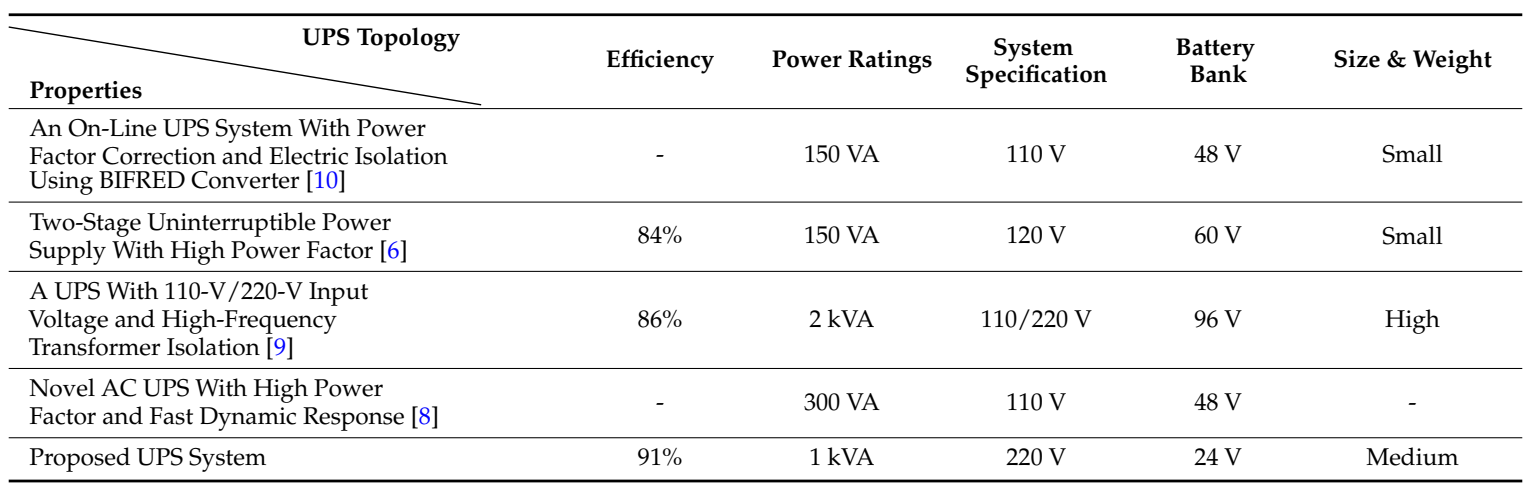

\section{Conclusions}

A single phase high-frequency transformer isolated online UPS has been proposed in this paper. A single-stage AC-DC converter provides galvanic isolation, efficient power conversion, and excellent power factor correction. Besides, the AC-DC converter also charges the battery bank of the UPS system during grid mode of operation. When there is a grid interruption, the low battery bank voltage is raised to high dc-link voltage using a boost converter which reduces the battery bank significantly. The boost converter provides high voltage gain with less number of active switches. A new inverter control of cascaded PR and SM control is used which provides regulated sinusoidal output voltage with low THD for both linear and non-linear load. Overall, the volume of the system is minimized by reducing the size, weight, and battery bank of the system. The experimental results show good dynamic and steady state performance.

\section{Authors Contribution}

All the authors contributed in finalizing the Paper. The main idea of the paper was presented by Muhammad Aamir while Wajaht Ullah Tareen and Kafeel Ahmed Kalwar helped in the control of the circuit. Mudasser Ahmed Memon prepared the format of the paper. Saad Mekhilef is the head of research team.

Acknowledgments: The authors would like to acknowledge the financial support from Bahria University, Islamabad, Pakistan.

Conflicts of Interest: The authors declare no conflict of interest.

\section{References}

1. Lahyani, A.; Venet, P.; Guermazi, A.; Troudi, A. Battery/supercapacitors combination in uninterruptible power supply (UPS). IEEE Trans. Power Electron. 2013, 28, 1509-1522. [CrossRef]

2. Zhao, B.; Song, Q.; Liu, W.; Xiao, Y. Next-generation multi-functional modular intelligent UPS system for smart grid. IEEE Trans. Ind. Electron. 2013, 60, 3602-3618. [CrossRef]

3. Branco, C.G.; Torrico-Bascope, R.P.; Cruz, C.M.; de A Lima, F. Proposal of three-phase high-frequency transformer isolation UPS topologies for distributed generation applications. IEEE Trans. Ind. Electron. 2013, 60, 1520-1531. [CrossRef]

4. Hwang, J.-C.; Chen, J.-C.; Pan, J.-S.; Huang, Y.-C. Measurement method for online battery early faults precaution in uninterrupted power supply system. IET Electr. Power Appl. 2011, 5, 267-274. [CrossRef]

5. Karve, S. Three of a kind [UPS topologies, IEC standard]. IEE Rev. 2000, 46, 27-31. [CrossRef]

6. Vázquez, N.; Villegas-Saucillo, J.; Hernández, C.; Rodríguez, E.; Arau, J. Two-stage uninterruptible power supply with high power factor. IEEE Trans. Ind. Electron. 2008, 55, 2954-2962.

7. Aamir, M.; Kafeel, A.K.; Mekhilef, S. Review: Uninterruptible power supply (UPS) system. Renew. Sust. Energy Rev. 2016, 58, 1395-1410. [CrossRef] 
8. Rodriguez, E.; Vázquez, N.; Hernández, C.; Correa, J. A novel AC UPS with high power factor and fast dynamic response. IEEE Trans. Ind. Electron. 2008, 55, 2963-2973. [CrossRef]

9. Torrico-Bascope, R.P.; Oliveira, D.S.; Branco, C.G.C.; Antunes, F.L.M. A UPS with 110-V/220-V input voltage and high-frequency transformer isolation. IEEE Trans. Ind. Electron. 2008, 55, 2984-2996. [CrossRef]

10. Nasiri, A.; Nie, Z.; Bekiarov, S.B.; Emadi, A. An on-line UPS system with power factor correction and electric isolation using BIFRED converter. IEEE Trans. Ind. Electron. 2008, 55, 722-730. [CrossRef]

11. Hirachi, K.; Yoshitsugu, J.; Nishimura, K.; Chibani, A.; Nakaoka, M. Switched-mode PFC rectifier with high-frequency transformer link for high-power density single phase UPS. In Proceedings of the IEEE 28th Annual IEEE Power Electronics Specialists Conference, (PESC'97 Record), St. Louis, MO, USA, 27 June 1997; Volume 1, pp. 290-296.

12. De Rooij, M.A.; Ferreira, J.A.; van Wyk, D. A novel unity power factor low-EMI uninterruptible power supply. IEEE Trans. Ind. Electron. 1998, 34, 870-877. [CrossRef]

13. Park, H.S.; Kim, C.H.; Park, K.B.; Moon, G.W.; Lee, J.H. Design of a charge equalizer based on battery modularization. IEEE Trans. Veh. Technol. 2009, 58, 3216-3223. [CrossRef]

14. Lee, Y.S.; Cheng, M.W. Intelligent control battery equalization for series connected lithium-ion battery strings. IEEE Trans. Ind. Electron. 2005, 52, 1297-1307. [CrossRef]

15. Zhang, Y.; Yu, M.; Liu, F.; Kang, Y. Instantaneous current-sharing control strategy for parallel operation of UPS modules using virtual impedance. IEEE Trans. Power Electron. 2013, 28, 432-440. [CrossRef]

16. Yang, S.; Chen, S.; Lin, J. Dynamics analysis of a low-voltage stress single-stage high-power factor correction AC/DC flyback converter. IET Power Electron. 2012, 5, 1624-1633. [CrossRef]

17. Duarte, J.; Lima, L.R.; Oliveira, L.; Michels, L.; Rech, C.; Mezaroba, M. Single-stage high power factor step-up/step-down isolated AC/DC converter. IET Power Electron. 2012, 5, 1351-1358. [CrossRef]

18. Ki, S.; Lu, D. Extension of minimum separable switching configuration modelling to single-stage AC/DC converters with direct power transfer. IET Power Electron. 2012, 5, 1154-1163. [CrossRef]

19. Yang, L.-S.; Liang, T.-J.; Chen, J.-F.; Lin, R.-L. Analysis and design of a novel, single-stage, three-phase AC/DC step-down converter with electrical isolation. IET Power Electron. 2008, 1, 154-163. [CrossRef]

20. Ma, H.; Ji, Y.; Xu, Y. Design and analysis of single-stage power factor correction converter with a feedback winding. IEEE Trans. Power Electron. 2010, 25, 1460-1470. [CrossRef]

21. Mahdavi, M.; Farzaneh-Fard, H. Bridgeless CUK power factor correction rectifier with reduced conduction losses. IET Power Electron. 2012, 5, 1733-1740. [CrossRef]

22. Abasian, A.; Farzaneh-fard, H.; Madani, S. Single stage soft switching AC/DC converter without any extra switch. IET Power Electron. 2014, 7, 745-752. [CrossRef]

23. Liang, T.-J.; Yang, L.-S.; Chen, J.-F. Analysis and design of a single-phase AC/DC step-down converter for universal input voltage. IET Electr. Power Appl. 2007, 1, 778-784. [CrossRef]

24. Lai, C.; Shyu, K. A single-stage AC/DC converter based on zero voltage switching LLC resonant topology. IET Electr. Power Appl. 2007, 1, 743-752. [CrossRef]

25. Lin, J.-L.; Yao, W.-K.; Yang, S.-P. Analysis and design for a novel single-stage high power factor correction diagonal half-bridge forward AC/DC converter. IEEE Trans. Circ. Syst. I Regul. Pap. 2006, 53, 2274-2286. [CrossRef]

26. Lu, D.-C.; Iu, H.-C.; Pjevalica, V. Single-stage AC/DC boost-forward converter with high power factor and regulated bus and output voltages. IEEE Trans. Ind. Electron. 2009, 56, 2128-2132. [CrossRef]

27. Choi, W.-Y.; Yoo, J.-S. A bridgeless single-stage half-bridge AC/DC converter. IEEE Trans. Power Electron. 2011, 26, 3884-3895. [CrossRef]

28. Ribeiro, H.S.; Borges, B.V. High-performance voltage-fed AC-DC full-bridge single-stage power factor correctors with a reduced DC bus capacitor. IEEE Trans. Power Electron. 2014, 29, 2680-2692. [CrossRef]

29. Das, P.; Pahlevaninezhad, M.; Moschopoulos, G. Analysis and design of a new AC-DC single-stage full-bridge PWM converter with two controllers. IEEE Trans. Ind. Electron. 2013, 60, 4930-4946. [CrossRef]

30. Erickson, R.W.; Maksimovic, D. Fundamentals of Power Electronics; Springer Science \& Business Media: New York, NY, USA, 2001.

31. Aamir, M.; Mekhilef, S.; Hee-Jun, K. High-gain zero-voltage switching bidirectional converter with a reduced number of switches. IEEE Trans. Circ. Syst. II Express Briefs 2015, 62, 816-820. [CrossRef]

32. Zargari, N.; Ziogas, P.; Joos, G. A two switch high performance current regulated DC/AC converter module. IEEE Trans. Ind. Appl. 1995, 31, 583-589. [CrossRef] 
33. Cortes, P.; Ortiz, G.; Yuz, J.I.; Rodriguez, J.; Vazquez, S.; Franquelo, L.G. Model predictive control of an inverter with output LC filter for UPS applications. IEEE Trans. Ind. Electron. 2009, 56, 1875-1883. [CrossRef]

34. Tamyurek, B. A high-performance SPWM controller for three-phase UPS systems operating under highly nonlinear loads. IEEE Trans. Power Electron. 2013, 28, 3689-3701. [CrossRef]

35. Komurcugil, H. Rotating-sliding-line-based sliding-mode control for single-phase UPS inverters. IEEE Trans. Ind. Electron. 2012, 59, 3719-3726. [CrossRef]

36. Abrishamifar, A.; Ahmad, A.A.; Mohamadian, M. Fixed switching frequency sliding mode control for single-phase unipolar inverters. IEEE Trans. Power Electron. 2012, 27, 2507-2514. [CrossRef]

37. Ullah, W.; Mekhilef, S. Transformer-less 3P3W SAPF (three-phase three-wire shunt active power filter) with line-interactive UPS (uninterruptible power supply) and battery energy storage stage. Energy 2016, 109, 525-536.

38. International Electro-technical Commission. Uninterruptible Power Systems (UPS)—Methods of Specifying the Performance and Test Requirements; IEC62040-3 Standard; IEC: Geneva, Switzerland, 1999.

(C) 2017 by the authors. Licensee MDPI, Basel, Switzerland. This article is an open access article distributed under the terms and conditions of the Creative Commons Attribution (CC BY) license (http://creativecommons.org/licenses/by/4.0/). 